\title{
Processo histórico de mudança de uma catequese escolar para educação religiosa escolar na Província Marista do Rio de Janeiro
}

\author{
Historical process of change of a Sunday school for religious education scholl in the Province of \\ Rio de Janeiro Marist
}

Sérgio Junqueira

Professor Titular, Livre Docente em Ciências da Religião. Programa de Pós-Graduação em Teologia, Coordenador do Grupo de Pesquisa Educação e Religião.

srjunq@gmail.com

RESUMO: De forma descritiva apresentar os modelos organizados para a área pastoral da Província Marista do Rio de Janeiro, tendo como condutor a disciplina hoje denominada Educação Religiosa Escolar, mas que inicialmente era conhecida como Aula de Religião. A fim de compreender os modelos propostos, serão apresentados alguns elementos que contextualizam e contribuem para caracterizar cada uma das etapas que se sucederam progressivamente. Especificamente sobre o desenvolvimento dessa disciplina na Escola Católica do Brasil, não encontrei outro autor, entretanto pude utilizar estudos que contextualizassem, como o do P. Lima ao abordar o movimento catequético no Brasil, ou do P. Tolentino, quando, em 1989, apresentou também uma tese de doutorado sobre a renovação da catequese no Brasil, ambas produzidas na Universidade Pontifícia Salesiana. Mas o grande referencial foi, sem dúvida, Thomas Kuhn, em seu livro: "As estruturas das revoluções científicas", ao tratar das questões referentes aos Paradigmas, referências que assumem significativo papel norteador nas decisões de homens e instituições. Para realizar tal pesquisa foi possível contar com uma certa quantidade de documentos da Instituição, sobretudo pelo acesso que me foi concedido aos Arquivos Gerais dos Irmãos Maristas, onde pude confrontar originais das circulares dos Superiores Gerais, com elementos dos Capítulos da Congregação e outros documentos do próprio Fundador. Uma grande contribuição foi à possibilidade de encontrar cópias das Circulares, Atas de Conselho, Boletins Informativos, Relatórios de diversos aspectos da Província Marista do Rio de Janeiro, no próprio Arquivo Geral. Além da contribuição direta da Comissão Pastoral Educativa, através do Escritório Central da UBEE. Um terceiro elemento enquanto orientação para a organização, seleção das fontes foram dadas por profissionais que vivenciaram este período histórico. Um quarto referencial foram os relatórios de cada Colégio Marista da Província, sintetizando o processo pastoral. Esse trabalho, organizado por mim quando membro da CPE, além de um grande relatório do processo de implantação do Programa Marista de Educação Religiosa, concluído em 1993, foi sem dúvida o marco que permitiu desenvolver toda essa pesquisa. Palavras Chave: Educação; Ensino Religioso; Educação Confessional.

ABSTRACT: Descriptively present models for organized pastoral area of the Province of Rio de Janeiro, with the driver discipline now called Religious Education School, but was initially known as Religion Class. In order to understand the proposed models, we introduce some elements that contribute to contextualize and characterize each of the steps that followed progressively. Specifically on the development of this discipline in a Catholic School in Brazil, I found no other author, however could use contextualizassem studies, such as P. Lima to address the catechetical movement in Brazil, or P. Tolentino, when, in 1989, also presented a doctoral thesis on the renewal of catechesis in Brazil, both produced at the Salesian Pontifical University. But the big reference was undoubtedly Thomas Kuhn, in his book: "The structure of scientific revolutions", to address issues relating to Paradigms, references that assume a significant role in guiding decisions of men and institutions. To accomplish this research was possible to have a certain amount of documents of the institution, especially for the access I was granted the General Archives of the Marist Brothers, where I could confront the original circular of Superiors General, with elements of Chapters of the Congregation and other documents Founder himself. A major contribution was the possibility of finding copies of Circulars, Minutes of Council, Newsletters, Reports of various aspects of the Province of Rio de Janeiro, the very General Archive. Besides the direct contribution of the Educative Pastoral Commission, through the Office of Central UBEE. A third element as a guideline for the organization, selection of sources were given by professionals who have experienced this historical period. A quarter references were reports of each Province of Marist College, summarizing the pastoral process. This work, edited by me as a member of the CPE, but a major report of the implementation process of the Marist Religious Education Program, completed in 1993, was arguably the milestone that allowed developing all this research.

Keywords: Education; Religious Education; Education Confessional. 


\section{Introdução}

O trabalho sobre o Ensino Religioso nas instituições escolares públicas é amplo, porém sobre as instituições particulares é muito restrito, este artigo apresenta as conclusões da pesquisa realizada sobre escolarização do Ensino Religioso nas Escolas Maristas da Província do Rio de Janeiro, ao longo deste processo foram verificados algumas questões relevantes como:

a) rever a história pastoral da Província, os caminhos, os desafios e conquistas ao longo dos anos, pois tinha como intenção realizar um processo consequencial e não um fato isolado.

b) estabelecer os paradigmas para orientar o trabalho da comissão PedagógicoPastoral Ao longo de uma longa discussão, ficou estabelecido os seguintes referenciais iniciais: Experiência Pastoral da Província, Orientações da Igreja e as características biopsicossociais de nossos alunos. Ao longo do processo estes paradigmas foram sendo aprofundados para melhor orientar a organização de um programa de Educação Religiosa.

c) envolvimento do maior número de profissionais ligados à escola, a fim de desenvolver um processo de corresponsabilidade da proposta que estava sendo organizada.

Posteriormente, questões surgiram, exigindo novas perspectivas, tais como: a formação dos professores e técnicos da escola, atualização dos roteiros de trabalho, produção de material, participação junto à Igreja local e outros de significativa importância.

A partir desta experiência, proponho sistematizar as informações obtidas ao longo do processo de produção do Programa de Educação Religiosa. Posteriormente poderá ser de contribuição para outras instituições de Educação Católica, pois percebo que existe uma carência nesta área no Brasil.

Por essas questões é que foi proposto através do desenvolvimento da pesquisa o seguinte objetivo realizar de forma descritiva apresentar os modelos organizados para a área pastoral da Província Marista do Rio de Janeiro, tendo como condutor a disciplina hoje denominada de Educação Religiosa Escolar, mas que inicialmente era conhecida como Aula de Religião. A fim de compreender os modelos propostas, serão apresentados alguns elementos que contextualizam e contribuem para caracterizar cada 
uma das etapas, que se sucederam progressivamente, e com alguns momentos de tensão que interferiram na operacionalização dos mesmos.

Pois sendo que a congregação Marista surgiu com a finalidade de fazer conhecer e amar Jesus Cristo. Neste espírito fundou o Instituo para a educação cristã de jovens e crianças. Com este espírito, os Irmãos Maristas se engajaram na ação pastoral da Igreja no Brasil, na América Latina.

A proposta do Ensino Religioso nasceu e desenvolveu no ambiente escolar a fim de responder de forma qualificada ao desejo da Igreja de ser presente também neste espaço.

Neste âmbito que surgiu o horizonte desta pesquisa foi a de apresentar uma proposta de escolarização dessa disciplina, com uma estrutura que garantisse sua identidade em um contexto da Escola Católica, que contribuísse a um processo de Evangelização de crianças e jovens. Que essas possam em seu período de experiência neste espaço de Igreja, ter a oportunidade de receber informações para que possam contribuir para o confronto de suas experiências, a fim de responder a um contexto de intensa e constante mudança, como cristãos e como cidadãos.

Portanto a hipótese desenvolvida foi a de a Província do Rio de Janeiro possui uma experiência de trabalho, de trinta e sete anos, e que ao longo de sua história teve que alterar sua proposta de trabalho. O questionamento era sobretudo:

+ Quais os modelos que a Província utilizou ao longo de sua história para responder ao objetivo da Congregação? Dentro desta questão, quais as variáveis interferiram para essa alteração?

Para responder a tal questão a bibliografia fundamental vieram dos documentos da Congregação, dos documentos da Igreja, livros- revistas referentes à história da catequese do período dos anos quarenta aos anos noventa. Quanto a historia da Província encontra-se nos textos dos arquivos da União Brasileira de Educação e Ensino, mas, sobretudo nos relatos feitos por Irmãos e professores que construíram a história.

A metodologia escolhida é do tipo comparativo, ou seja, a partir dos elementos da história da Província confrontar com elementos presentes na história da Igreja - dos movimentos catequéticos, aspectos da história da Igreja Latino-Americana, história do Ensino Religioso Estatal brasileiro, Orientações da Igreja (Universal, Continental e 
Nacional), além de aspectos da história da educação.

Nesse processo de pesquisa do contexto confrontando com o processo, só foi possível através do seguinte material: programas, relatos e pequenos documentos. Que foram sistematizados em três momentos, em três estágios de desenvolvimento desta disciplina: Aula de Religião (modelo Dedutivo - doutrinal), Aula de Formação Cristã ou/e Formação Religiosa (modelo Indutivo e Ativo) e finalmente a Educação Religiosa (modelo Hermenêutico Antropológico - VER, JULGAR e AGIR).

Na busca da compreensão das variáveis, que interferiram nesse processo, que se transformaram em paradigmas de ação. Outro aspecto presente ao longo do trabalho foi o melhor compreender a atual proposta que necessita ser repensada em sua estrutura a fim de atualizar-se e contextualizar, para poder responder as alterações sociais e ser fiel ao objetivo do Instituto.

Para tal foi desenvolvido a pesquisa com a seguinte estrutura, inicialmente uma abordagem da origem e desenvolvimento da Congregação dos Irmãos Maristas e seu trabalho de serviço a Sociedade e a Igreja na Educação Católica. Posteriormente foi sistematizado o primeiro e o segundo período da história da estruturação da disciplina religioso sendo o primeiro período de 1958 a 1968, fase de organização da Província, e a perspectiva ainda da disciplina como AULA DE RELIGIÃO. No segundo período com o início 1968, quando acontece o XVI Capítulo Geral, a partir do qual existe um grande movimento de renovação da Congregação, ao mesmo tempo exige o repensar à identidade do Irmão Marista. Neste segundo período sob o influxo do processo de renovação europeia dos anos quarenta a sessenta, a grande entrada dos leigos, existe uma significativa mudança do perfil da disciplina, que passa a ser denominado de FORMAÇÃO RELIGIOSA ou FORMAÇÃO CRISTÃ, o acento é dado sobre o aluno, suas atividades. A terceira parte inicia com a publicação do PROGRAMA Marista de Pré-escola, que sob o influxo de novos referenciais pedagógicos, orientados a fim de operacionalizar a Educação Evangélica Libertadora, inicia uma maior preocupação com a escolarização desta disciplina, que recebe o nome de Educação Religiosa, com um novo programa. Este terceiro capítulo organizado em seis partes, onde se apresenta desde a origem até a sua primeira avaliação, ou seja, de 1989 a 1995, com elementos referentes à produção, implantação, implementação e formação de pessoal para aplicar a proposta realizada no ano de 1995. 
Um exigente percurso de mudança... Um ideal...

A Província Marista do Rio de Janeiro, em sua experiência no período de trinta e sete anos (1958-1995) de atuação junto à sociedade brasileira, educando crianças e jovens, é fruto de uma longa herança, iniciada com um ideal proposto pelo $\mathrm{P}$. Champagnat:

“Guiado pelo Espírito, Marcelino Champagnat foi cativado pelo amor de Jesus e de Maria para com ele e para com os outros. Essa vivência, como também sua abertura aos acontecimentos e às pessoas, está na origem de sua inspiração e de seu zelo apostólico. Ela o torna sensível às necessidades de seu tempo, especialmente à ignorância religiosa e às situações de pobreza da juventude.

Sua fé e desejo de cumprir a vontade de Deus revelam-lhe sua missão: 'Fazer conhecer e amar Jesus Cristo'. Dizia muitas vezes: 'Não posso ver uma criança, sem sentir o desejo de ensinarlhe o catecismo, sem desejar fazer-lhe compreender quanto Jesus Cristo a amou'.

Nesse espírito, fundou nosso Instituto para a educação cristã dos jovens, particularmente os mais abandonados 1 ".

A proposta de Marcelino prosseguiu por meio de seus Irmãos, que progressivamente expandem sua presença pelos cinco continentes:

“O P. Champagnat encarna zelo apostólico que sabe dar respostas adequadas a problemas concretos. Sente-se chamado a formar religiosos para a educação cristã dos pequenos camponeses, dos quais ninguém se ocupa.

Para ele, a missão do Irmão consiste em ajudar as crianças e os jovens a se tornarem 'bons cristãos e bons cidadãos'.

Homem de fé acredita primeiro na oração que torna dócil o coração dos alunos. O exemplo e a presença prolongada são elementos importantes da pedagogia Marista que ele assim resume: 'Para educar bem as crianças é preciso amá-las'.

Irmãos Maristas, animados de igual zelo, continuamos o carisma do Fundador respondendo aos anseios e às necessidades dos jovens de hoje $\mathrm{e}^{2}$.

Os Irmãos, no final do século XIX, foram convocados por diversos Bispos do Brasil, a fim de contribuir no projeto de evangelização do país, através da Educação formal - A ESCOLA:

"A escola Marista oferece às famílias uma proposta educativa em que se harmonizam fé, cultura e vida, na óptica de Marcelino Champagnat. Essa proposta insiste nos valores de esquecimento de si mesmo e de abertura aos outros. Apresenta a cultura como meio de comunhão entre os homens, e o saber como dever de serviço.

Em nossas escolas, ambiente privilegiado de educação cristã, damos prioridade à pastoral adaptada às expectativas dos jovens. Disponíveis a todos, damos atenção especial aos alunos em dificuldade.

Abertas a todas as famílias que aceitam a proposta educativa, nossas escolas promovem o diálogo entre as pessoas de culturas e confissões diferentes ${ }^{3}$ ".

\footnotetext{
${ }^{1}$ C. n. 02.

2 lb., n. 81.

3 lb., n. 87.
} 
Ao longo de quase um século de presença Marista no Brasil (1897-1995), existe um desejo, e muitas vezes explicitamente realizado, de como Consagrados participarem do movimento eclesial, a fim de que o anúncio de Jesus se faça de fato em comunhão com a comunidade - Igreja, mesmo se ao longo dos anos, nem sempre esse desejo, que faz parte da própria origem da Congregação, tenha sido vivenciado em sua plenitude.

\begin{abstract}
"Cresce nas pessoas consagradas a consciência de que têm de ser na Igreja particular promotoras de comunhão, quer pelo significado de sua consagração na Igreja, como pelo testemunho de universalidade da mensagem evangélica que supera as diferenças de toda a espécie: raciais, culturais, tribais, etc; quer pela sua solidariedade e disponibilidade para com todos, especialmente os mais pobres; quer ainda porque dessa forma se colocam como laço de união entre a Igreja e os grupos marginalizados, que muitas vezes não são atingidos pela pastoral ordinária ${ }^{4}$.
\end{abstract}

O trabalho realizado nas escolas da Província, considerando o período de 1958 a 1995, no que se refere à Evangelização, foi sem dúvida resultada de uma série de paradigmas que se sucederam ao longo desse período entre os quais: a proposta do Fundador, as orientações da Igreja e o processo histórico da sociedade.

Essa história se organizou em três períodos, assim constituídos:

1) De 1958 a 1968: Uma proposta pedagógica, fundada sobretudo no academicismo, onde a tradição dos Colégios Maristas, baseada no volume de informações, na seriedade dos professores/religiosos que eram, possuía uma rígida formação, considerada como padrão de qualidade. A área religiosa compunha-se das Aulas de Religião, ministradas através dos Catecismos, de característica metodológica dedutivo-doutrinal. Paralelamente ao espaço das salas de aulas, havia alguns movimentos para os alunos, como a Cruzada Eucarística, clima de aprofundamento doutrinal e de piedade. Esse período, que tem como importante evento o repensar da Igreja sobre si mesma e sua relação com o mundo, eclode no Concílio Vaticano II, com todo o seu processo de renovação.

Tal experiência eclesial foi fruto de uma longa e árdua história de renovação, através dos movimentos litúrgico, bíblico e kerigmático. Desde o final do XIX, com o Movimento de Munique, por exemplo, a Catequese, vinha construindo um novo itinerário, enriquecido pelas inovações psicopedagógicas. No Continente Latinoamericano, paralelo a esse processo, nascia o desejo de um rosto latino da Igreja, que

\footnotetext{
4 SÍNODO DOS BISPOS (IX Assembléia Geral Ordinária), A vida consagrada e a sua missão na Igreja e
} no mundo, Vaticano Libreria Editrice Vaticana, 1994, n. 73. 
possui uma longa história de evangelização, expressa, sobretudo a partir da II Conferência do Episcopado do continente (1968), que visava traduzir para a América a proposta do Concílio Vaticano II.

O nível sócio-político-econômico é tumultuado para diversos países desse Continente, com a imposição de vários Golpes de Estado, inclusive o Brasil, que, a partir de 1964, sofreu a perda dos direitos humanos, com a dominação da direção do país pelos Chefes Militares. O país passa pela era do chamado "Milagre Brasileiro". São diversas as transformações que promovem consequências, inclusive no comportamento, na estrutura social do país.

Diante de um significativo quadro de novas necessidades, os Irmãos Maristas, reunidos em seu XVI Capítulo Geral, que aconteceu no período de 1967-1968, estavam convocados pela Igreja para reverem suas Regras, a fim de adequá-las ao novo processo eclesial e social.

No início dessa primeira fase, de fato, a grande tradição metodológica era quase exclusivamente dedutivo-doutrinal, mas, progressivamente, foi crescendo a sensibilidade de estar atento a outras variáveis que deveriam interferir no processo de organizar os programas das aulas, assim como as estratégias e outros elementos. Segundo o Sínodo sobre a Catequese, que aconteceu em 1977, do qual resultou a Exortação Apostólica "Catechesi Tradendae", os Bispos concluíram que:

\footnotetext{
"A variedade nos métodos é um sinal de vida e uma riqueza. Foi assim que a consideraram os Padres da IV Assembléia Geral do Sínodo, ao chamarem a atenção para as condições indispensáveis, a fim de que tal variedade seja útil e não prejudicial à unidade do ensino da única fé ${ }^{5}$.
}

2) De 1968 a 1988: - A Província Marista do Rio de Janeiro, em seu Primeiro Capítulo Provincial, em 1969, iniciou o processo de reorganização a fim de responder às novas demandas. Um elemento significativo surgiu, até então considerado de forma diferente, ou seja, a atuação dos Irmãos junto aos pobres, apelo reivindicado de forma especial a partir de Medellín, que encontrou eco na Congregação, especialmente na sensibilidade do então Superior Geral, Ir. Basílio Rueda. Era necessário buscar novas frentes de trabalho a fim de ser coerente com a própria origem do Instituto.

Paralelo a esse apelo, surge um significativo problema: a perda de efetivo, pois

${ }^{5}$ CT, n.51. 
diversos Irmãos deixam a Congregação. A Província, no período de 1974 a 1975, viu-se obrigada a fechar os seguintes Colégios: Brasília (DF), Varginha, Poços de Caldas, São Vicente de Minas e Patos de Minas (MG). O início dos anos setenta caracteriza-se pelo chamado ao discernimento, dos Irmãos perante a Igreja e a sociedade.

Nas Escolas Maristas, prossegue o processo de uma educação caracterizada pela seriedade e qualidade pedagógica, com uma alteração: progressivamente, a presença dos Irmãos é reduzida, as aulas, a coordenação dos trabalhos e mesmo a direção das escolas são entregues aos "Leigos". Surge a necessidade de organizar um processo central de orientação das escolas. Ao longo dos anos, sob denominações diversas, estrutura-se o trabalho pedagógico e pastoral, a fim de conduzir os Colégios. A essa equipe, desde a sua origem, foi entregue a função de contribuir na orientação e Educação Marista, de qualidade, que respeitasse a proposta do fundador e lhe fosse fiel. Para tal deveria organizar a formação dos professores e técnicos, assim como elaborar subsídios para os trabalhos em todos os níveis.

Ao longo da década de setenta, a Província assume uma educação tecnicista, com todas as consequências dessa concepção de educação. Paralelamente a essa opção, o Setor de Pastoral sofre uma série de modificações, com uma forte característica catequético-paroquial. A disciplina nesse período é denominada Formação Religiosa ou Formação Cristã. Não existe uma proposta única. Cada Escola utiliza o material e o programa que deseja, ou que percebe que melhor se adequa aos seus alunos. Entretanto, progressivamente, o movimento extraclasse assume uma grande vitalidade, com projetos que atingem o trabalho junto aos alunos (Projeto Maria de Nazaré), os professores (Mater Fidei) e os funcionários (Projeto Maria de Caná).

Sobretudo no final dos anos setentas e na primeira metade dos anos oitentas, cresce o interesse de estabelecer uma proposta mínima para todas as escolas da Província, o que facilitaria a produção de subsídios e, sobretudo a formação dos professores.

Tais propostas nascem em um contexto importante. Em 1976, acontece o XVII Capítulo Geral, que vem reforçar o desejo de uma participação maior dos Irmãos junto à população pobre, nova presença Marista na Igreja. Esse apelo é reforçado pela III Conferência Episcopal Latino americano em Puebla (México/1979).

O processo de modernização do planeta, novas conquistas tecnológicas, novas 
legislações - tais como aprovação do aborto e do divórcio, em alguns países, assim como os diversos movimentos juvenis de contestação - produzem um novo rosto social e cultural no planeta, que interfere no Brasil, e, portanto, um novo perfil de aluno surge em nossas escolas.

A fim de responder a tantas variáveis, a Província assume obras junto a localidades carentes, com uma nova perspectiva de presença dos Irmãos. O Setor Pedagógico Pastoral assume a proposta de organizar uma Educação Evangélicolibertadora, proposta desde Medellín, o que acarretou um repensar toda a escola, o currículo como um todo.

A opção pedagógica que respondia a essa proposta Pastoral era o Construtivismo, tendo como teórico de referência o epistemologista Jean Piaget. Posteriormente, tem acrescido por Vigotsky, Leontiev e Luria, sem esquecer a importante contribuição de Emília Ferreira.

No ano de 1985, com o XVIII Capítulo Geral, e a aprovação definitiva das novas Constituições e Estatutos, a Província de fato recebia um referencial significativo para orientar, ou melhor, confirmar sua proposta de trabalho.

Em 1988, inicia a aplicação do Conteúdo Mínimo de Formação Religiosa, fruto de um longo trabalho, através do qual estava estabelecido um roteiro mínimo a ser utilizado em todas as escolas. Paralelo a essa aplicação estava sem andamento a Escola de Catequese por Correspondência, além de alguns encontros, a fim de contribuir na formação dos professores dessa disciplina.

Progressivamente a equipe pedagógica da Província, inicia a produção dos programas das diversas disciplinas em uma perspectiva evangélico-libertadora. Dessa forma contribuindo para um novo passo no programa da área religiosa.

Metodologicamente existe uma mudança de uma proposta dedutiva-doutrinal, para uma concepção indutiva. Tal perspectiva metodológica tem sua origem nessa segunda fase, mas tomará envergadura na terceira fase. Consiste basicamente na apresentação de fatos, tais como: os acontecimentos bíblicos, atos litúrgicos, a vida da Igreja e o cotidiano do aluno. Considerando esses elementos em vista de uma análise, por parte do corpo discente, com a finalidade de descobrir a significação que possui no mistério cristão.

Tais métodos estão em conformidade com a economia da Revelação e 
correspondem a uma das características fundantes do espírito que chega às realidades inteligíveis partindo dos elementos visíveis, assim como é também conforme as características do conhecimento da fé, que acontece através dos sinais ${ }^{6}$. Estrategicamente, existe um acento a considerar significativamente a experiência do aluno, partindo de sua estrutura bio-psicológica, de sua realidade, para estruturar um itinerário, de educação religiosa ${ }^{7}$.

Uma proposta... (1988 a 1995)

A partir da publicação do Conteúdo Mínimo (CM), o esforço de um trabalho em conjunto das Unidades da Província, tornou-se cada vez mais possível. É um momento em que a crise econômica do país agrava-se progressivamente, ao longo dos anos noventas, o número de alunos sofre uma redução, inclusive como consequência do processo pedagógico pastoral. O padrão de qualidade das escolas é questionado, diversas são as variáveis que interferem no nome da escola junto à sociedade.

As pesquisas pedagógicas prosseguem, é publicado o Programa Marista de Educação Pré-escolar, posteriormente o Programa de Matemática para a Primeira Fase. Curso de extensão ou correspondência é estruturado, para qualificar os professores. Existe um forte acento de atenção à Pré-escola e à Primeira Fase. Gradativamente são repensadas as demais séries.

No que se refere à área religiosa, a partir de 1989, inicia um processo de revisão do Conteúdo mínimo em vista da produção de um Programa que desse uma unidade às escolas, fosse de fato um norteador. Em 1991, foram publicados os dois primeiros volumes do Programa Marista de Educação Religiosa e, posteriormente, em 1992, os dois últimos.

Uma das questões ao longo do processo de revisão do CM foi o de repensar a estrutura da disciplina, pretendia-se de fato escolarizar essa área, aproximá-la pedagogicamente, não somente o reorganizar de conteúdos e estratégias. Um sinal dessa mudança foi à alteração da denominação enquanto disciplina. Assumiu a estrutura de Educação Religiosa. Os referenciais para essa proposta foram: o resultado da aplicação do Conteúdo Mínimo, as Orientações da Igreja, a coerência com a proposta pedagógica

${ }^{6}$ Cf. DCG, n. 72

7 Cf. lb., n. 74. 
e a adequação com o processo de desenvolvimento bio-psico do aluno.

Sobretudo a partir de 1991, existe um acento no processo de sala de aula: os movimentos extraclasses sofrem uma significativa perda de qualidade, sendo posteriormente retomados. A proposta metodológica iniciada no período anterior (19681988) é, sem dúvida, de característica do método da correlação, segundo um modelo Antropológico-kerigmático.

A escolarização da disciplina acontece, sobretudo a partir da reflexão do Magistério da Igreja no Brasil, expresso através do documento sobre a Catequese, da Conferência dos Bispos do Brasil - "Catequese Renovada", que afirma:

\begin{abstract}
"O ensino religioso nas escolas é normalmente distinto da Catequese nas comunidades. Para o cristão, é particularmente importante para conseguir a síntese criteriosa entre a cultura e a fé. Não tratamos aqui dos problemas específicos do ensino religioso, que deve 'caracterizar-se pela referência aos objetivos e critérios próprios da estrutura escolar' (cf. João Paulo II, Discurso de 5.3.1981,3). Mas o ensino religioso levará em conta, nas devidas proporções, o que aqui é dito a respeito da Catequese em Comunidade, com a qual mantém 'íntima conexão' nos destinatários e no conteúdo. Devido ao pluralismo religioso da sociedade em que vivemos no ensino religioso nas escolas deverá prevalecer a evangelização, cabendo a Catequese à comunidade paroquial ${ }^{8}$ ".
\end{abstract}

Essa alteração na percepção sobre o ensino religioso é consequência de uma concepção de Igreja, promovida a partir do Concílio Vaticano II, como povo de Deus, que caminha ao longo da história, em uma Nova Aliança (cf. LG n. 24). A Igreja, assembléia dos cristãos, comunidade redenta, o Reino de Deus, o povo da Nova Aliança, na qual se realiza a antiga promessa feita a Israel ${ }^{9}$. O Documento da Catequese Renovada afirma que:

“A renovação atual da Catequese nasceu para responder aos desafios de uma nova situação histórica. Esta exige a formação de uma comunidade cristã missionária que anuncie, na sua autenticidade, o Evangelho e o torne fermento de 'comunhão e participação' na sociedade e de libertação integral do homem." 10

A escola é parte dessa missão da Igreja, por esse motivo o Documento do Departamento de Catequese do CELAM - "Linhas Comuns", propõe:

“A escola católica se relacionará também com a vida da comunidade paroquial e diocesana, procurara a integração de seus alunos em sua paróquia como membros ativos, dispostos a participar das riquezas da vida litúrgica e pastoral da Igreja. Compete ainda à escola católica

${ }^{8}$ CR, n. 125.

${ }^{9}$ Cf. L. CHIAPPETTA, Prontuário di Diritto Canonico e concordatario, Bologna Ed. Dehoniane, 1994, 205.

${ }^{10}$ CR, n. 30. 
buscar uma vinculação cada vez mais estreita com a família e estender sua ação evangelizadora ${ }^{11}$ ".

Recorda ainda o documento que:

"A escola, como instituição educativa, deverá preocupar-se em considerar o 'Ensino Religioso' como elemento fundamental da ação educativa orientada a conseguir uma síntese adequada entre a fé e a cultura, dando uma visão cristã da realidade ${ }^{12}$ ".

Percebe-se, ao longo da história da Província, uma preocupação, nem sempre explícita, de promover um verdadeiro movimento pastoral. Três aspectos persistem: um primeiro, ligado à organização de uma equipe, que favoreça os projetos, organizando, acompanhando e avaliando. Ainda sobre esse aspecto, à Província teve diversos Informativos ou Boletins, que contribuíram em propagar as idéias, os fatos que estavam sendo desenvolvidos. Um segundo aspecto está ligado à preocupação com a formação, inicialmente apenas dos Religiosos Maristas e, posteriormente, numa significativa proporção, para os leigos. Progressivamente percebe-se que os Irmãos se afastam da atualização no que se refere à pastoral escolar. Cursos, Semanas de Estudos, assinaturas de revistas foram estratégias ao longo da história pastoral da Província. Um terceiro aspecto é a seleção e mesmo produção de subsídios e programas que explicitam as idéias em vigor em cada momento.

Em paralelo, é possível perceber uma preocupação em acompanhar as Orientações da Igreja, procurando operacionalizá-las através do movimento pastoral provincial, ao menos por parte dos responsáveis pelo setor. A pedagogização da pastoral foi crescente, até chegar à explicitação de estabelecer uma coerência entre o processo pedagógico e pastoral, não apenas no aspecto de estratégia, mas no campo filosófico teórico. Por outra a Pastoralização do pedagógico, que seria um ideal, encontra dificuldades de ser operacionalizada em nome da "qualidade de ensino", promovendo um desequilíbrio entre o pastoral e o pedagógico.

O caminho da Igreja, a evolução sócio-cultural-econômica, a reflexão do Instituto e mais as pesquisas psicopedagógicas são os referenciais, sobre os quais o processo pastoral das escolas da Província Marista do Rio de Janeiro, tem traçado seu itinerário. Nem sempre tal processo é consciente, explícito.

${ }^{11}$ CELAM/DECAT, Catequese na América latina. São Paulo Ed. Paulinas, 1986, n. 172.

12 lb., n. 171. 
Ao longo dessa história, percebe-se que os passos sempre foram fruto de pesquisas, de atenção aos sinais dos tempos. Entretanto, a estrutura teórica, que justificasse a explicitação do caminho, não é um dos aspectos mais fortes.

Uma das consequências é o processo de avaliação, que parte de críticas empíricas, ou seja, como a base teórica do material utilizado ao longo dos anos na Província é frágil, consistindo basicamente no aspecto de organização de conteúdo e estratégias, com paradigmas em geral não explicitados. $\mathrm{O}$ que dificulta o diálogo com professores, Irmãos e técnicos, que fundamentalmente partem de suas experiências, não sistematizadas, de leituras desatualizadas, sobretudo da falta de conhecimento do magistério da Igreja, e, portanto permanece um desafio traçar um itinerário consciente coletivo de alteração nessa área.

Entretanto é possível continuar em busca de propostas pedagógico-pastorais mesmo diante do aspecto ressaltado anteriormente, pois a legislação do país permite certa liberdade de ação nos Colégios, pois a Constituição Brasileira, afirma que:

“Art. 209. O ensino é livre à iniciativa privada, atendidas as seguintes condições:

I - cumprimento das normas gerais da educação nacional;

II - Autorização e avaliação de qualidade pelo Poder Público. ${ }^{13}$ ”.

Outro suporte para orientar o processo é sem dúvida o Magistério da Igreja, tem se mostrado sensível às transformações do contexto. Afirma no Diretório Catequético Geral, publicado em 1971, pela Sagrada Congregação para o Clero, que a civilização chamada científica, técnica industrial e urbana não irão distrair a atenção dos homens do aspecto religiosos, e lhes torna mais difícil à solicitude interna para a vida religiosa ${ }^{14}$. Verificam-se de fato transformações cada vez maiores nas comunidades tradicionais, nos diferentes grupos e nas relações sociais. Já foi o tempo em que a cristandade, a religião era considerada como o princípios mais importante da unidade dos povos, bem diversa é de fato a situação atual, a coesão dos povos que tem sua origem no fenômeno da democratização promove a concórdia das diferentes famílias espirituais, o chamado pluralismo religioso ${ }^{15}$.

Pois de fato, uma confluência revolucionária de mudanças tecnológicas

\footnotetext{
${ }^{13}$ Constituição da República Federativa do Brasil, Brasília Senado Federal, 1988, 139.

14 DCG, n. 05.

15 Cf. lb., n. 03.
} 
organizou um novo ambiente que dotará os indivíduos de mais poder do que em qualquer outra época do passado. A partir, sobretudo do desenvolvimento rápido, acelerado das telecomunicações, elabora-se de fato um sistema maior a serviço do protagonista menor, o indivíduo. $\mathrm{O}$ acento das partes em vista do todo é consequência de uma grande mutação de comportamento, de organização social ${ }^{16}$. Paralelamente a essa nova dimensão do indivíduo, cria-se uma nova concepção de regras de conduta, exige-se, sobretudo nas relações uma ética, uma postura de honestidade, retomada de posições até então esquecidas, ou então consideradas ultrapassadas, o que altera de fato o processo de socialização e de internacionalização do homem moderno ${ }^{17}$.

Nesse quadro, a Igreja alerta que um dos grandes desafios para que ela possa ser de fato sinal, através de seus agentes e/ou de suas estruturaras, entre as quais a escola, é o testemunho real da proposta que a Igreja se propõ $\mathrm{e}^{18}$ :

“A falta deste testemunho é um obstáculo à aceitação da Palavra por parte dos ouvintes ${ }^{19}$ ".

Essa mesma Igreja recorda aos religiosos o seu papel, a sua importância em atuarem de fato na missão da evangelização:

"Há muitas famílias religiosas, masculinas e femininas, que nasceram para a educação cristã das crianças e dos jovens, sobretudo dos mais abandonados. No correr da história, o Religioso e as Religiosas encontraram-se muito comprometidos na atividade catequética da Igreja, realizando nesse campo um trabalho particularmente adaptado e eficaz. E estando nós numa altura em que se querem acentuar os laços entre os religiosos e os pastores e, por consequência, a presença ativa das Comunidades religiosas e dos seus membros nos planos pastorais da Igreja locais, nós exorto-os de todo o coração - a vós, a quem a consagração religiosa, há de tornar ainda mais disponíveis para o serviço da Igreja - a que vos prepareis o melhor possível para a tarefa da Catequese, segundo as diversas vocações dos vossos institutos e as mais os que vos são confiadas, levando convosco por toda a parte esta preocupação. E que as comunidades consagrem o máximo das suas capacidades e das suas possibilidades ${ }^{20}$ ".

O Papa João Paulo II, nessa mesma Exortação, recorda às escolas católicas, que elas devem de fato procurar serem sinais na sociedade, que sua categoria de escolas da Igreja não deve ser apenas como um adjetivo vazio de conteúdo. Não basta possuírem uma alta qualidade de ensino no que se refere às diversas disciplinas ${ }^{21}$.

Como reposta a esse apelo, os Províncias da América latina, comprometeram-se,

${ }^{16}$ Cf. J. NAISBITT, Paradoxo Global. Rio de Janeiro Ed. Campus, 1994 2a., 315 ss.

17 Cf. Ib., 169 e 170.

18 Cf. DCG, n . 35.

19 lb., n. 35.b.

${ }^{20}$ CT, n.65.

${ }^{21}$ Cf. lb., n. 69. 
desde 1987, a formar o Irmão em comunhão com a Igreja, sensível à cultura local, sobretudo um consagrado entre as crianças e os jovens:

"Um Irmão capaz de viver em comunhão com a Igreja particular e universal; de assumir as orientações da Igreja latino-americana em sua opção preferencial pelos jovens e pelos pobres; de sentir-se o povo de Deus e capaz de amá-la, apesar de suas imperfeições ${ }^{22}$ ".

Para tal é preciso que os Religiosos e leigos que atuam nesse espaço sócio eclesial se preocupam com sua formação e, sobretudo atualização, sensibilização à história. As Constituições e Estatutos dos Irmãos Maristas recordam que:

"A necessidade de uma formação permanente estende-se à vida inteira e a todas as suas dimensões. Temos, pois, o grave dever de continuar nossa formação, a fim de responder aos apelos divinos sempre renovados e de viver mais profundamente nossa vocação com nossos Irmãos ${ }^{23} "$.

A fim de operacionalizar tal aspecto constitucional, o Guia da Formação, aprovado pelo XIX Capítulo Geral, apresenta o seguinte objetivo para a Formação permanente:

“A formação inicial tem o arremate com a profissão perpétua. Começa então a formação permanente, que dura à vida toda. Situa-se ao mesmo tempo num contexto histórico e pessoal. Por um lado, o período em que vivemos de mutações rápidas, exige abertura do coração e de espírito, atualização contínua. Por outro, toda pessoa é um ser inacabado, em devir; assim, o batizado ou a pessoa consagrada 'procura se tornar adulto em Cristo' (C. 110). Nesse contexto, a formação permanente apresenta objetivo duplo: o desenvolvimento da pessoa e a construção do Reino de Deus. O primeiro objetivo está em função do segundo. ${ }^{24 "}$.

“O objetivo do desenvolvimento da pessoa do Irmão não é outro senão a realização mais eficaz de nossa missão: 'fazer conhecer e amar Jesus Cristo' (C.02). No campo da missão, importa responder 'aos apelos divinos sempre renovados 'de viver mais plenamente 'nossa vocação com nossos Irmãos' (C. 110), desenvolvendo a abertura e a sensibilidade 'aos sinais dos tempos', aos apelos da Igreja e às necessidades da juventude' (C.168) ${ }^{25}$ ".

O processo de buscar uma coerência, um caminho de resposta aos apelos da Igreja e da sociedade é, sem dúvida, um percurso não concluído, que a cada instante exige maior sensibilização. Tal consciência foi expressa pelos Irmãos reunidos no XIX

22 "O perfil do Irmão Marista que desejamos formar hoje na América Latina", n. 06. In. CONFERÊNCIA LATINO AMERICANA DOS PROVÍNCIAS, Chosica e Cáli: um apelo e uma esperança, para o Irmão Marista na América latina. Roma Casa Geral, 1987.

23 C., n. 110.

${ }^{24}$ FMS, Guia da Formação do Instituto dos Irmãos Maristas das Escolas. São Paulo Ed. Loyola, 1993, n. 358.

25 Ib., n. 364. 
Capítulo Geral, em sua mensagem final a todos os Irmãos:

"Nós Irmãos Maristas, reunidos em Capítulo, depois de analisar a situação do mundo, da Igreja e do Instituto, depois de proclamar as convicções sobre a Nossa Missão, queremos partilhar com vocês, para sublinhá-los, alguns aspectos dela que nos interpelaram com especial insistência e que continuarão a questionar nossas decisões e prioridades:

- A primazia do testemunho em relação às palavras, no anúncio de Jesus Cristo e da Boa Nova.

- A necessidade de inculturar-nos para inculturar a mensagem evangélica.

- A solidariedade na opção pelos pobres e na luta pela justiça manifestada em nossa vida pessoal e comunitária e em nossas instituições apostólicas.

- O compromisso na Igreja local, com todo o Povo de Deus, para construir comunhão em solidariedade.

- A importância do laicato na missão da Igreja, e em nossa Missão de Irmãos Maristas, Irmãos e leigos, participaram todos da Missão de Jesus.

- O valor da educação cristã na escola, com atenção especial a estes aspectos da evangelização: o anúncio de Jesus Cristo, a educação à solidariedade e ao compromisso para a transformação da sociedade, a integração da fé e da cultura, a prioridade das ações pastorais, a criação de espaços de fraternidade ${ }^{26}$ ".

No que se refere à escola, declaram:

"Nós nos comprometemos a formar uma Escola Marista mais evangelizadora:

- onde a Comunidade Educativa possa partilhar a fé, a celebração e nos sacramentos;

- onde os Irmãos e os leigos vivam a fraternidade com os jovens e testemunhem os valores evangélicos;

- onde se garanta a educação integral;

- onde se desenvolva a educação, baseada na justiça e na solidariedade, empenhando os jovens em ações concretas.

Uma escola:

- que forme jovens de fé pessoal em Jesus e compromissados com os valores e a missão da escola;

- que estabeleça o diálogo entre fé, cultura e vida, conforme a ótica de Champagnat;

- que apresente Maria como modelo do cristão;

- que faça da presença entre os alunos elemento importante da educação ${ }^{27}$."

O futuro do mundo e da Igreja pertence à nova geração, que nasceu neste século, amadurecerá no próximo, o primeiro de um novo milênio. Cristo prossegue perguntando aos jovens: “Que cosia deve fazer de bom para obter a vida eterna?” (cf. Mt 19,16). As novas gerações são convidadas a responder a essa pergunta com a vida, com a sensibilidade aos novos tempos, às novas exigências. A Igreja, através de seus educadores tem a responsabilidade de realizar propostas, audaciosas e $\operatorname{criativas}^{28}$, a fim de contribuir para que o sinal de Jesus Cristo, através de suas comunidades possa prosseguir, a ser presença transformadora no mundo.

${ }^{26}$ FMS, Atas do XIX Capítulo Geral dos Irmãos Maristas das Escolas. Roma Casa Geral, 1993, n. 20.

27 lb., n. 31.

${ }^{28}$ Cf. GIOVANNI PAOLO II, Tertio Millennio Adveniente. Vaticano Libreria Editrice Vaticana, 1994, n. 58. 
Os educadores das escolas Maristas são convidados a participar na organização de um contínuo movimento pastoral, não como MESTRES, mas, sobretudo como testemunhas ${ }^{29}$.

Essa história prossegue de fato, no compromisso que será concretizado, através da sensibilidade aos novos sinais, atentos às tendências de nossa sociedade e à fidelidade à missão do Instituto em comunhão com a Igreja. Nesse sentido a Igreja do Brasil, propõe para o próximo quadriênio (1995-98 o seguinte objetivo:

“Em preparação do seu jubileu do ano 2.000, na força do espírito que o Pai nos enviou, sob a proteção da Mãe de Deus e nossa, queremos:

EVANGELIZAR, com renovado ardor missionário, testemunhando Jesus Cristo, em comunhão fraterna, à luz da evangélica opção preferencial pelos pobres, para formar o povo de Deus e participar da construção de uma sociedade justa e solidária, a serviço da vida e da esperança nas diferentes culturas a caminho do Reino Definitivo ${ }^{30}$ ".

Entretanto o processo de operacionalização desse referencial, aparenta ser conduzido por novos paradigmas, de fato o país, a Igreja, as estruturas sócio-políticareligiosas apresentam sinais de novas tendências, que encontram certo suporte no referencial social, é necessário estar atento e sensível para responder aos novos apelos do contexto em vista da fidelidade à missão ${ }^{31}$.

\section{Considerações Finais}

Foi possível identificar, nomear e caracterizar os três importantes momentos pastorais da Província. O referencial básico foi sem dúvida a disciplina religiosa, através dos subsídios utilizados, de sua estrutura pedagógica e características pastorais foi possível perceber o desenvolvimento do processo de evangelização nas escolas maristas. Partindo de uma catequese escolar, sendo o núcleo o conteúdo, onde a escola repetia a prática religiosa das paróquias. Entretanto diante de uma série questionamentos tal modelo progressivamente vai sendo repensado, sobretudo com a crescente preocupação com aluno, sujeito do processo, são elaboradas diversas propostas, com uma base metodológica fundamentalmente indutiva ativa, com forte acento antropológico.

${ }^{29}$ Cf. B. ARBUÉS, Mensagem audiovisual do Superior Geral (texto). Roma Casa Geral, 1994, Mimeo.

${ }^{30}$ Cf. M. LENS, A 33a. Assembléia Geral da CNBB. In. RBR (Religiosos Brasileiros em Roma) n. 122, Julho de 1995. Roma Mimeo., 02.

${ }^{31}$ Cf. V. CODINA, Creo en el Espiritu Santo - Pneumatologia narrativa, (Col. Presencia Teológica) Maliaño Sal Terrae, 1994, 144. 
Ao longo dessa história, sem dúvida o passo importante foi à elaboração do Conteúdo Mínimo, procurando articular a definição de um conteúdo e o desenvolvimento dos alunos, segundo elementos psicopedagógicos. A sua revisão, produziu o Programa Marista de Educação Religiosa, que na tentativa de explicar a identidade da disciplina, procurou.

\section{Referenciais}

ARBUÉS,B. Mensagem audiovisual do Superior Geral (texto). Roma Casa Geral, 1994, Mimeo.

CELAM/DECAT, Catequese na América latina. São Paulo Ed. Paulinas, 1986.

CHIAPPETTA,L. Prontuário di Diritto Canonico e concordatario, Bologna Ed. Dehoniane, 1994.

CODINA,V. Creo en el Espiritu Santo - Pneumatologia narrativa, (Col. Presencia Teológica) Maliaño Sal Terrae, 1994.

CONFERÊNCIA NACIONAL DOS BISPOS DO BRASIL, Catequese Renovada - orientações e conteúdo (Documento n. 26), São Paulo, Paulinas, 1983.

CONGREGAÇÃO PARA O CLERO, Diretório Geral para a Catequese, 15 agosto 1997, São Paulo, Paulinas, 1998.

Constituição da República Federativa do Brasil, Brasília Senado Federal, 1988.

FMS, Constituições e Estatutos dos Irmãos Maristas. São Paulo, Loyola, 1986.

FMS. Atas do XIX Capítulo Geral dos Irmãos Maristas das Escolas. Roma Casa Geral, 1993.

FMS. Guia da Formação do Instituto dos Irmãos Maristas das Escolas. São Paulo Ed. Loyola, 1993.

GIOVANNI PAOLO II. Tertio Millennio Adveniente. Vaticano Libreria Editrice Vaticana, 1994.

JOÃO PAULO II, Exortação Apostólica sobre a Catequese no nosso tempo - Catechesi Tradendae, 16 outubro 1979, Petrópolis, Vozes, 19844.

LENS,M. A 33a. Assembléia Geral da CNBB. In. RBR (Religiosos Brasileiros em Roma) n. 122, Julho de 1995. Roma Mimeo.

NAISBITT,J. Paradoxo Global. Rio de Janeiro Ed. Campus, 1994 2a.

O perfil do Irmão Marista que desejamos formar hoje na América Latina”. In. CONFERÊNCIA LATINO AMERICANA DOS PROVÍNCIAS, Chosica e Cáli: um apelo e uma esperança, para o Irmão Marista na América latina. Roma Casa Geral, 1987.

SÍNODO DOS BISPOS (IX Assembléia Geral Ordinária), A vida consagrada e a sua missão na Igreja e no mundo, Vaticano Libreria Editrice Vaticana, 1994.

Recebido:21/02/2013

Received: 02/21/2013

Aprovado: 04/07/2013

Approved: 07/04/2013 